\title{
PENERAPAN LOCATION BASE SERVICE UNTUK MEMPERKENALKAN HOTEL DAN WISATA KULINER DI KOTA PEKALONGAN BERBASIS AUGMENTED REALITY
}

\author{
Wachid Darmawan*, Ichwan Kurniawan, Akhmad Fuady Rifqiyanto \\ STMIK Widya Pratama Pekalongan \\ Jl. Patriot No.25 Pekalongan, (0285) 427816, 427817
}

Korespondensi: wachid.dw@gmail.com,

\begin{abstract}
Pekalongan City is one of the batik producers in the national even international level. Besides batik tourism, Pekalongan City also has many interesting places that need to be explored. Therefore many hotels and culinary tours have sprung up. The obstacle faced by tourists is the number of hotels and culinary locations which are quite difficult to detect because they are not on the Pantura line. Responding to these problems, it is necessary to make an application that can handle these problems, one of them is the application of location based service to introduce hotels and culinary tours in the city of Pekalongan based on augmented reality. In making the application using the waterfall method used for software development. As for the collection of data using observation and interview methods. This application can find out the destination location and the information available at its destination. By using the application you can find out the destination location in more detail, because in the application can know the position of the location to be located on the right or the left, so it's easier to find the location. To develop the application to the next stage the developer can add location and user usage engine usage. In addition to the layar to find out the level of accuracy between existing engines.
\end{abstract}

Keywords: Local base service, Hotels, Culinary tours, Augmented reality, Layar

\section{PENDAHULUAN}

\subsection{Latar Belakang}

Kota Pekalongan mempunyai potensi yang sangat besar karena berada di jalur pantura yang posisinya berada di tengah-tengah pulau Jawa. Kota Pekalongan merupakan salah satu central produsen batik di Indonesia, penjualannya sudah masuk skala nasional bahkan internasional. Selain wisata batik Kota Pekalongan juga mempunyai potensi wisata lainya, seperti: obyek wisata alam dan buatan, perhotelan, wisata kuliner dan wisata belanja. Dengan potensi yang ada di Kota Pekalongan banyak bermunculan Hotel-hotel, terdiri dari 33 hotel yang ada, di antaranya: 10 hotel bintang dan 23 hotel non bintang (Indriastuti, 2018).

Berdasarkan data yang tercatan di Badan Pusat Statistik Provinsi Jawa Tengah menunjukkan bahwa rata-rata jumlah pengunjung hotel bintang sekitar 757.300 dan non bintang sekitar 474.400 pada tahun 2018. Sedangkan untuk jumlah restoran atau rumah makan ada sekitar 100an lokasi yang ada di Kota Pekalongan (Indriastuti, 2018). Dengan banyaknya hotel dan rumah makan diharapkan dapat meningkatkan kunjungan wisatawan ke Kota Pekalongan.

Saat ini dinas terkait sudah banyak melakukan promosi di antaranya menggunakan pameran-pameran, melalui brosur, spanduk, website maupun sosial maedia. Dari beberapa media promosi yang sudah digunakan masih terdapat beberapa kendala, seperti: update informasi yang kurang cepat, lokasi yang dituju tidak dicantumkan dan lain sebagainya. Untuk itu perlu suatu teknologi yang mana 
bisa mengakomodir permasalah tersebut. Salah satu teknologi yang bisa digunakan adalah Location Base Service (LBS) berbasis Augmebted Reality (AR).

LBS adalah suatu layanan berbasis lokasi yang dapat digunakan di semua perangkat mobile yang sudah mendukung Global Positioning System (GPS) (Quercia, Lathia, Calabrese, Lorenzo, \& Crowcroft, 2011). Dengan kata lain LBS dapat dijadikan layanan yang dapat digunakan seseorang untuk menunjukkan lokasi yang akan dituju, seperti lokasi objek wisata atau hotel. Sedangkan untuk AR sendiri bekerja berdasarkan citra yang disematkan di dalam sebuah marker (Risty, 2012).

Dengan adanya teknologi yang semakin berkembang potensi wisata Kota Pekalongan bisa dimaksimalkan promosinya dengan memanfaatkan LBS berbasis AR. untuk itu pada penelitian ini berjudul Penerapan Location Base Service Untuk Memperkenalkan Potensi Wisata Kota Pekalongan Berbasis Augmented Reality. Yang bertujuan untuk meningkatkan pendapatan daerah dan bisa meningkatkan perekonomian masyarakat sekitar objek wisata karena banyaknya kunjungan wisatawan.

\subsection{Rumusan masalah}

Adapun permasalahan yanga ada pada penelitian ini adalah bagaimana cara menerapankan teknologi Location Base Service berbasis Augmented Reality untuk memperkenalkan hotel dan wisata kuliner di Kota Pekalongan?

\subsection{Tujuan Penelitian}

Tujuan penelitian yang akan dicapai adalah terciptanya Penerapan Location Base Service untuk Memperkenalkan Hotel dan Wisata Kuliner di Kota Pekalongan berbasis Augmented Reality.

\subsection{Landasar Teori}

\subsubsection{Location Based Service (LBS)}

LBS adalah suatu layanan berbasis lokasi yang dapat digunakan di semua perangkat mobile yang sudah mendukung Global Positioning System (GPS) (Quercia, Lathia, Calabrese, Lorenzo, \& Crowcroft, 2011). Dengan kata lain LBS dapat dijadikan layanan yang dapat digunakan seseorang untuk menunjukkan lokasi yang akan dituju, seperti lokasi objek wisata atau hotel. Untuk itu LBS dibedakan berdasarkan jenisnya (Imaniar, Arifin, \& Khalilullah, 2012), seperti:

1) Pull Service: layanan yang diberikan sesuai dengan reques dan kebutuhan pelanggan, seperti membuka website berita yang ada di internet.

2) Push Service: layanan yang diberikan kepada provaider tanpa menunggu reques dari pelanggan, tetapi informasinya sesuai dengan kebutuhan pelangganya.

Ada dua unsur yang ada di LBS (Safaat, 2013), di antaranya:

1) Location Manager (API Maps) adalah dalam API maps terdapat fasilitas yang dapat digunakan untuk memanipulasi peta yang ada

2) Location Provider (API Location) adalah dalam API location bisa mengetahui lokasi terdekat dengan kita menggunakan data GPS yang ada di perangkat atau smartphone 
Penggunaan teknologi LBS adalah penggabungan antara tiga tehnologi sekaligus, di antaranya: GIS, Internet Service dan Mobile Device. Tehnologi LBS juga fokus terhadap posisi yang sedang digunakan (metode positioning), seperti yang ada di gambar 1 .

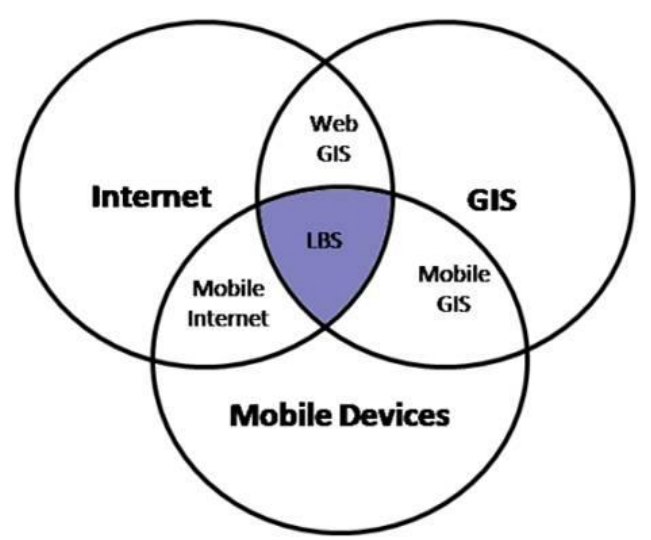

Gambar 1: Teknologi Location Based Service

\subsubsection{Augmented Reality (AR)}

AR adalah suatu teknologi yang dapat digunakan untuk menggabungkkan grafis komputer dengan dunia nyata (Toan \& Choo, 2010). AR sendiri bekerja berdasarkan citra yang disematkan di dalam sebuah marker (Risty, 2012). Pada saat memindai market ada dua metode yang dapat dilakukan (Rachman \& Wahyudi, 2014), di antaranya:

1) Marker Augmented Reality (Marker Based Tracking): aplikasi AR akan memindai marker yang disimbolkan menggunakan warna hitam dan putih. Aplikasi AR akan mendeteksi titik-titik yang ada dimarker, yaitu titik $(0,0,0)$ dan 3 sumbu $X, Y$, dan Z.

2) Markerless Augmented Reality: teknologi terbarukan dari AR, jadi tidak perlu lagi membuat marker karena menggunakan bantuan GPS berdasarkan lokasi yang sudah ditandai sebelumnya.

\subsubsection{Point of Interest (POI)}

POI adalah lokasi yang digunakan pengguna untuk menandai lokasi secara dinamis menyesuaiakan lokasi user (Satoto \& Rahmanita, 2013). Penambahan lokasi POI harus memperhatikan: lokasi pengguna, banyaknya POI disekitar pengguna, jarak antar POI dan lokasi pengguna.

\section{METODOLOGI PENELITIAN}

\subsection{Metode Pengumpulan Data}

Metode yang digunakan dalam penelitian ini antara lain:

2.1.1. Observasi

Pada penelitian ini melakukan kunjungan ke tempat-tempat wisata potensial dan hotel-hotel yang ada di Kota Pekalongan dan melakukan pencatatan titik koordinatnya. Yang mana titik-titik tersebut akan dijadikan sebagai titik POI untuk dimasukkan kedalam LBS. Berdasarkan data yang diperoleh dari kunjungan langsung ke lokasi Hotel dan beberapa Wisata Kuliner didapatkan hasil titik koordinat, data tersebut digunakan sebagai data POI. Yang mana data tersebut digunakan untuk mengetahui lokasi 
objek dan bisa dijalankan menggunakan aplikasi LBS yang sudah dibuat, berikut titik koordinat terlihat di tabel 1 .

Tabel 1 Titik Koordinat Latitude dan Longitude

\begin{tabular}{llcc}
\hline No. & Hotel dan Wisata Kuliner & Latitude & Longitude \\
\hline 1. & Hotel Sahid Mandarin & -6.905910 & 109.700550 \\
\hline 2. & Nirwana Hotel & -6.891478 & 109.680348 \\
\hline 3. & Hotel Namira Syariah & -6.889113 & 109.679039 \\
\hline 4. & The Sidji Hotel & -6.889603 & 109.678583 \\
\hline 5. & Hotel Pesona & -6.889199 & 109.676706 \\
\hline 6. & Hotel Hayam Wuruk & -6.888453 & 109.673052 \\
\hline 7. & Hotel Santika & -6.888738 & 109.664048 \\
\hline 8. & Hotel Horison & -6.888677 & 109.663426 \\
\hline 9. & Istana Hotel & -6.888959 & 109.662704 \\
\hline 10. & Hotel Indonesia & -6.888701 & 109.662128 \\
\hline 11. & Hotel Dafam & -6.901525 & 109.664569 \\
\hline 12. & Sego Rakyat Mbak Ibah & -6.887440 & 109.678618 \\
\hline 13. & Nasi Uwet H. Zarkasi & -6.889390 & 109.671091 \\
\hline 14. & Garang asem H. Masduki & -6.901299 & 109.675638 \\
\hline 15. & RM. Sop Buntut Bu Leman & -6.900493 & 109.680372 \\
\hline 16. & Nasi Megono RM Tjukup & -6.884867 & 109.672335 \\
\hline 17. & Rumah Makan Puas & -6.882581 & 109.677591 \\
\hline 18. & Soto Tauto H. Rochmani & -6.889342 & 109.661234 \\
\hline 19. & Soto Tauto PPIP Bu Bawon & -6.897828 & 109.680614 \\
\hline 20. & Soto Bang Dul & -6.902828 & 109.687724 \\
\hline
\end{tabular}

\subsubsection{Interview}

Pada penelitian ini melakukan wawancara kepada Dinas Pariwisata, Kebudayaan, Kepemudaan dan Olahraga Kota Pekalongan. Wawancara dilakukan secara terstruktur dan melakukan tatap muka secara langsung dengan staf terkait. Berikut tabel wawancara yang sudah dilakukan pada penelitian ini:

Tabel 2 Wawancara dengan Dinas Terkait

\begin{tabular}{|c|c|c|}
\hline No. & Pertanyaan & Jawaban \\
\hline 1. & $\begin{array}{l}\text { Saat ini apakah ada media/alat } \\
\text { bantu untuk mengenalkan } \\
\text { hotel dan wisata kuliner yang } \\
\text { ada di Kota Pekalongan? }\end{array}$ & $\begin{array}{l}\text { Media yang digunakan saat ini masih } \\
\text { sebatas menggunakan brosur, pamlet } \\
\text { dan media cetak lainya. Serta mengikuti } \\
\text { beberapa pameran yang diadakan di } \\
\text { Kota Pekalongan atau kota-kota lainya }\end{array}$ \\
\hline 2. & $\begin{array}{l}\text { Apakah saat ini sudah ada } \\
\text { sistem informasi yang bisa } \\
\text { membantu wisatawan untuk } \\
\text { mengetahui hal tersebut? }\end{array}$ & $\begin{array}{l}\text { Kalau berupa sistem sudah ada di } \\
\text { smartphonenya masing-masing, berupa } \\
\text { peta digital/google maps }\end{array}$ \\
\hline 3. & $\begin{array}{l}\text { Kendala apa yang dihadapi } \\
\text { dengan menggunakan sistem } \\
\text { tersebut? }\end{array}$ & $\begin{array}{l}\text { Kendalanya adalah wisatawan tidak bisa } \\
\text { mengetahui secara pasti posisinya } \\
\text { sekarang dan posisi lokasi yang akan } \\
\text { dituju. }\end{array}$ \\
\hline 4. & $\begin{array}{l}\text { Jika akan dibuatkan aplikasi } \\
\text { LBS, bagaimana gambaran } \\
\text { aplikasi tersebut? }\end{array}$ & $\begin{array}{l}\text { Aplikasi diharapkan bisa memberikan } \\
\text { informasi dan navigasi yang lebih } \\
\text { dinamis agar arah lokasi yang akan } \\
\text { dituju bisa lebih mudah dipahami oleh } \\
\text { wisatawan, serta data yang ada bisa } \\
\text { lebih up to date lagi. }\end{array}$ \\
\hline
\end{tabular}




\subsection{Pengembangan Perangkat Lunak (MPL)}

Untuk membangun aplikasi LBS menggunakan metode MPL, pada MPL yang digunakan dalam penelitian ini mengacu pada metode pengembangan sistem Watelfall (Pressman \& Maxim, 2015):

\subsubsection{Communication}

Tahap ini melakukan komunikasi dengan pihak terkait dan melakukan identifikasi kebutuhan sistem dan kebutuhan hardware. Pada tahap komunikasi melakukan diskusi dengan Dinas Pariwisata, Kebudayaan, Kepemudaan dan Olahraga Kota Pekalongan untuk mengetahui sistem yang dibutuhkan seperti apa. Pada tahap indentifikasi kebutuhan sistem digunakan untuk mengetahui aplikasi apa saja yang akan digunakan untuk membuat aplikasi LBS dan pada kebutuhan hardware digunakan untuk mengetahui perangkat mobile yang mendukung aplikasi LBS jika sudah selesai.

\subsubsection{Planning (Estimating, Scheduling, Tracking)}

Pada tahap ini lebih banyak membahas kebutuhan sistem, berupa kebutuhan fungsional dan non fungsional serta melakukan penjadwalan ke pada tim peneliti agar waktu yang sudah ditentukan bisa dimaksimalkan. Dan apabila ada kekurangan waktu bisa dilakukan penangan dengan cepat karena planing waktu yang sudah ditentukan sebelumnya.

\subsubsection{Modelling}

Pada tahap ini akan membuat desain sistem yang menggunakan UML, UML yang digunakan adalah diagram use case dan activity. Diagram use case digunakan untuk menyajikan interaksi antara aktor dan sistem. Sedangkan diagram activity akan mendeskripsikan logika prosedural pada sistem.

Pada tahapan perancangan model pada pembuatan aplikasi local base service menggunakan Unified Modeling Language (UML) (Sutejo, 2016), di antaranya:

1) Use Case Diagram

Use Case Diagram digunakan untuk menyajikan interaksi antara aktor dan sistem, yang aktor dapat berinteraksi dengan sistem yang sedang di bangun, seperti pada Gambar 2.

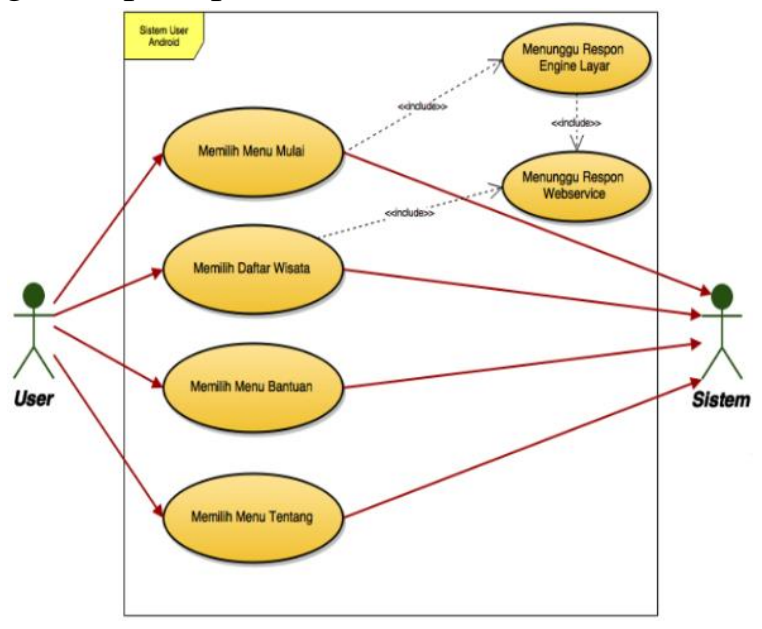




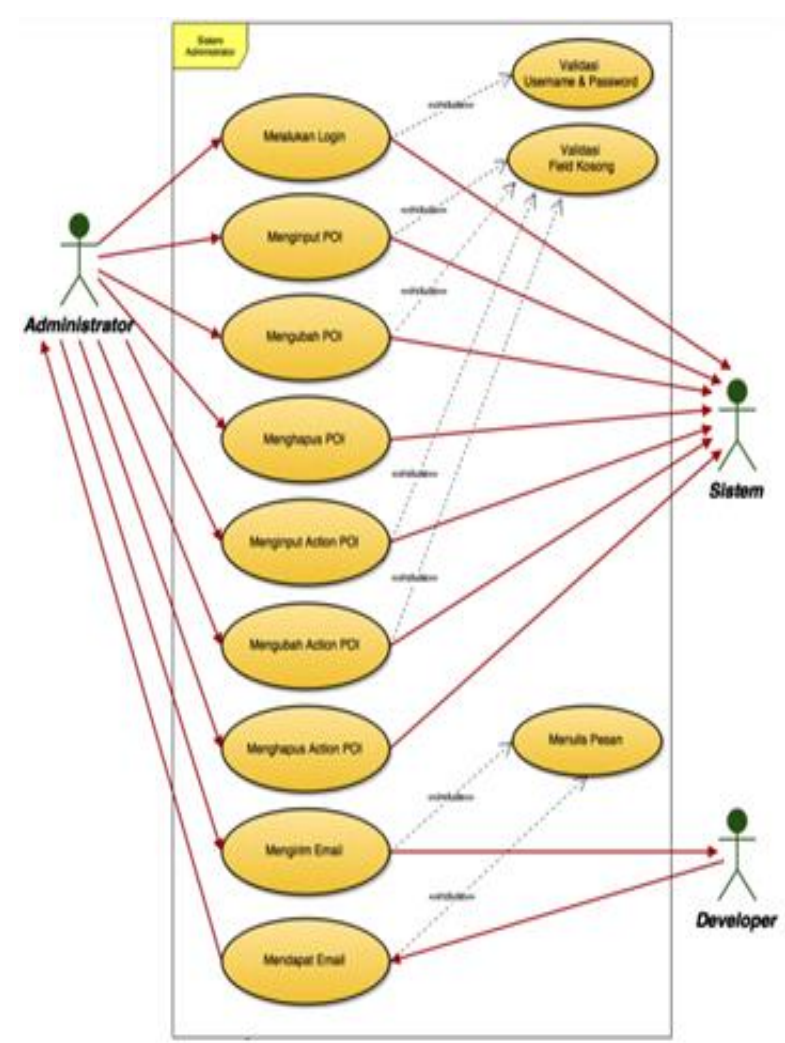

Gambar 2 Use Case Diagram pada Administrator dan User/Pengguna

2) Activity Diagram

Activity diagram akan mendeskripsikan logika prosedural pada sistem, proses bisnis pada sistem dan aliran kerja dalam berbagai kasus, pada activity diagram bisa mendukung perilaku paralel, seperti pada Gambar 3 dan Gambar 4:

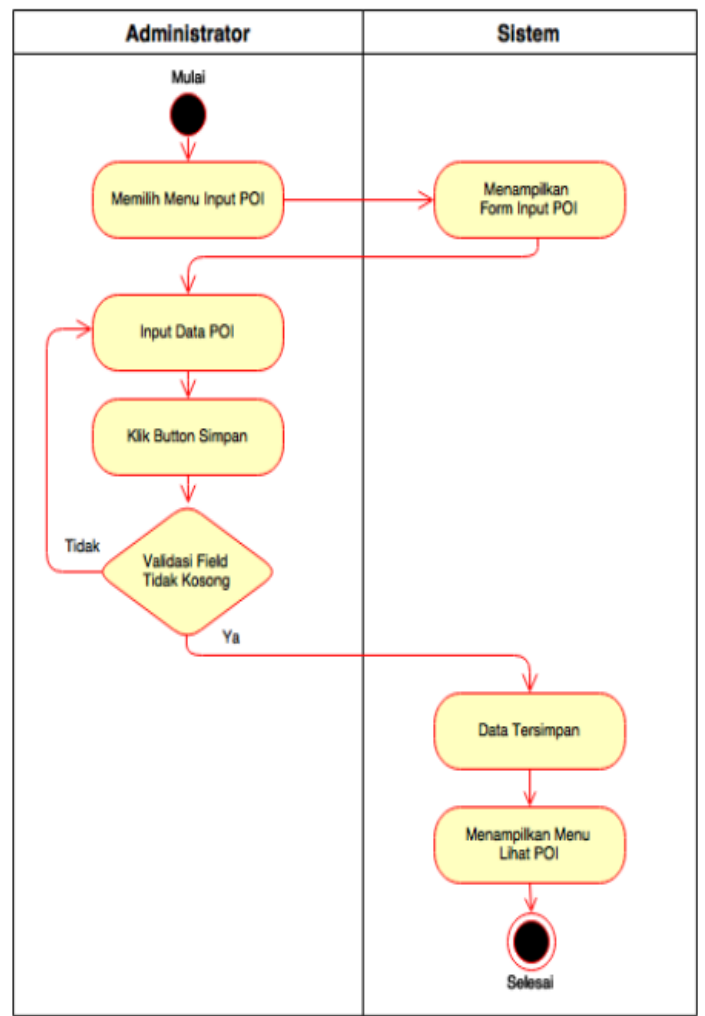

Gambar 3 Activity Diagram Input POI 


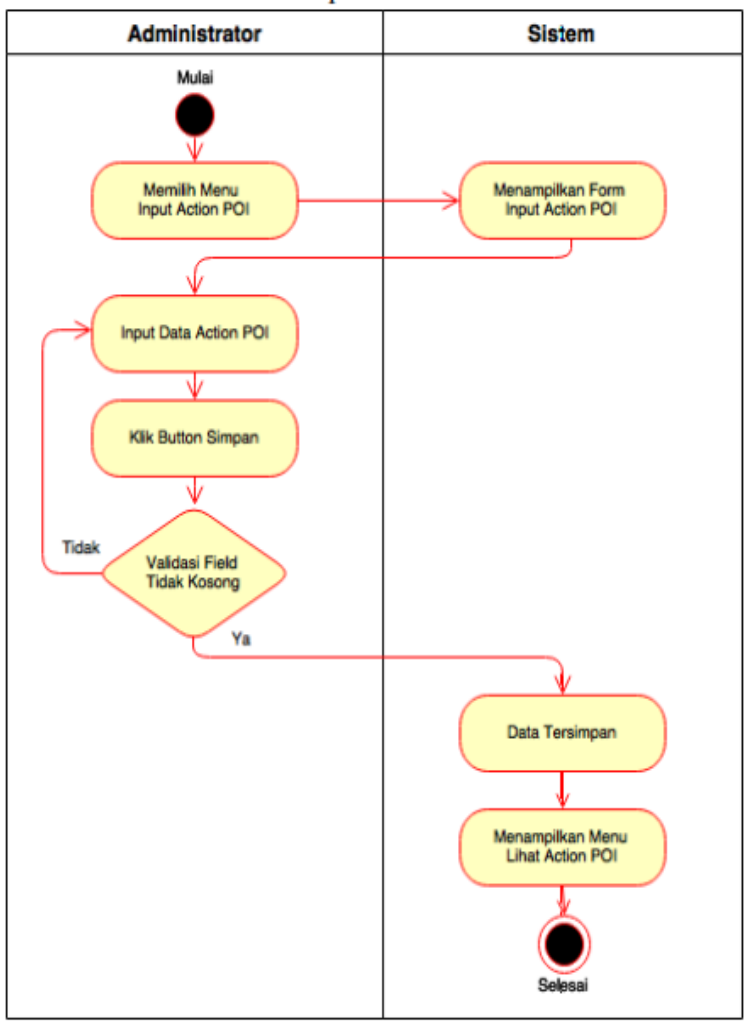

Gambar 4 Activity Diagram Input Action POI

\subsubsection{Construction}

Pada tahap ini melakukan pembuatan aplikasi LBS menggunakan bahasa perogram HTML, CSS serta PHP untuk membuat website berdasarkan diagram use case dan activity yang sudah dibuat. Selain membuat website juga membuat database agar website yang dibangun lebih dinamis jika ada perbahan. Untuk tampilan user/penggunakan menggunakan aplikasi android studio, berikut gambaran pembuatan aplikasinya, pada gambar 5 dan 6.

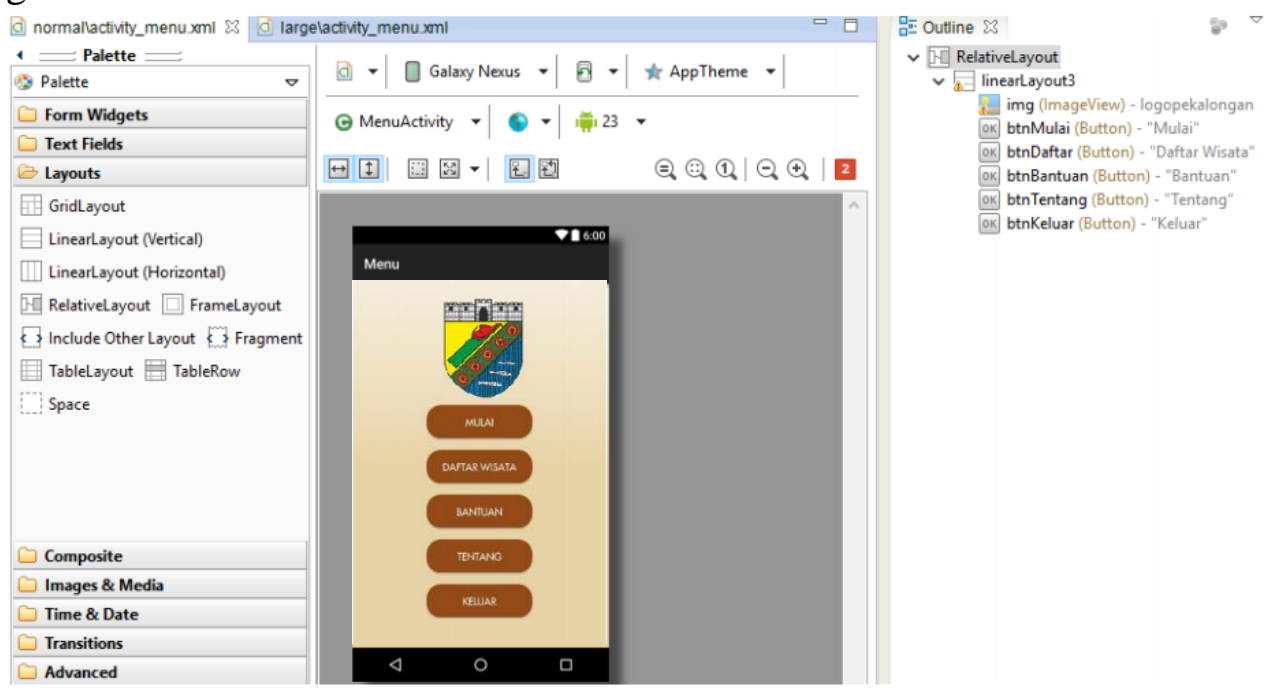

Gambar 5 Construction Menu Utama User/Pengguna 


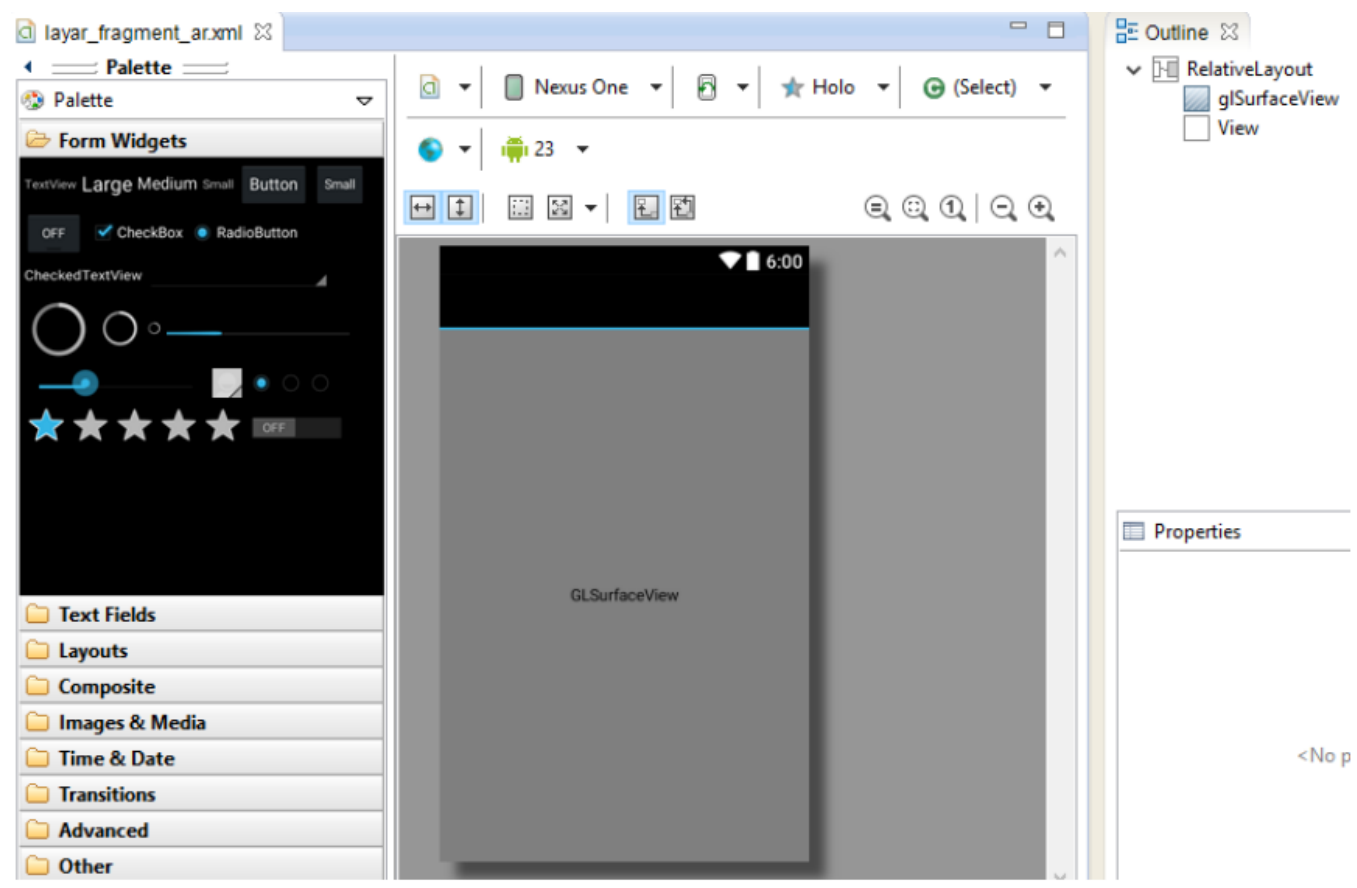

Gambar 6 Construction Augmented Reality

\subsubsection{Deployment}

Pada tahap ini akan dilakukan diskusi kepada pihak terkait mengenai aplikasi yang sudah dibuat, bila mana dikemudian hari terdapat fitur baru atau bug maka aplikasi ini akan diperbaiki sebagaimana mestinya.

\section{HASIL DAN PEMBAHASAN}

\subsection{Hasil Sistem/Aplikasi}

Berdasarkan titik koordinat yang sudah dikumpulkan pada tapan pengumpulan data, kemudian titik-titik koordinat tersebut dimasukkan kedalam aplikasi LBS yang sudah dibangun. Berikut tampilan aplikasi untuk bagian administrator dan user/pengguna, seperti pada gambar 7, 8 dan 9 .

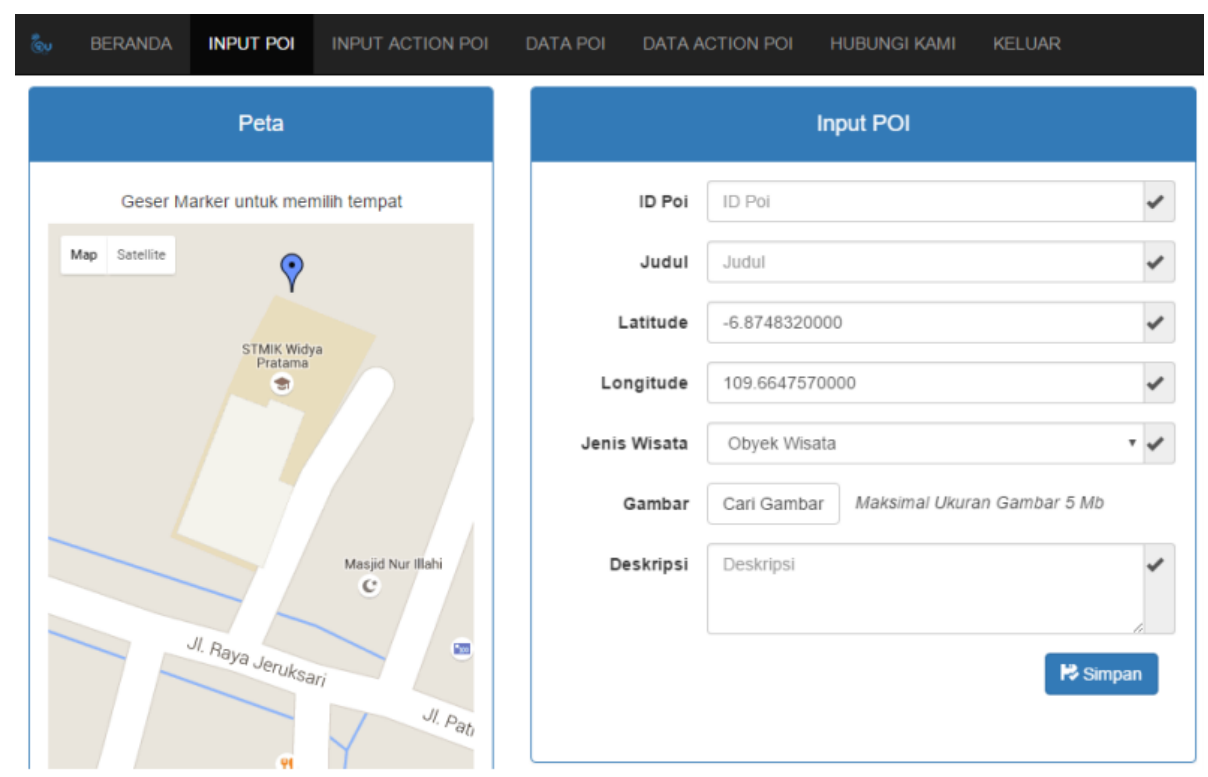

Gambar 7 Halaman Input POI 


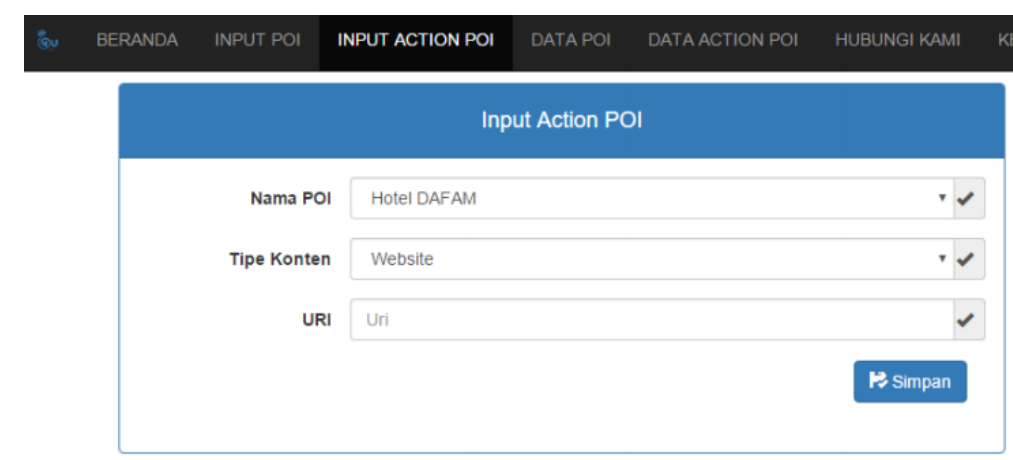

Gambar 8 Halaman Input Action POI

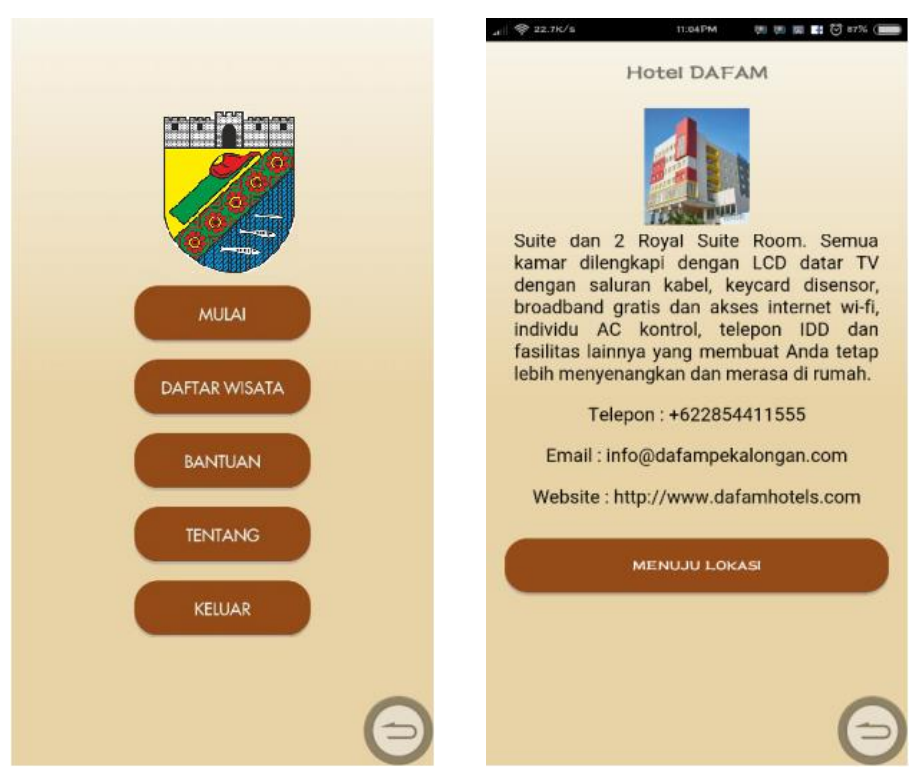

Gambar 9 Halaman Untuk User/Pengguna

\subsection{Pembahasan}

Hotel dan wisata kuliner yang ada di Kota Pekalongan semakin hari semakin banyak dan berkembang, sehingga memunculkan beberapa pilihan bagi wisatawan untuk menentukan hotel mana yang akan dipilih. Selama ini proses pengenalan hotel dan wisata kuliner masih menggunakan brosur dan medai cetak lainya. Dari pihak hotel juga melakukan pendekatan ke beberapa agen travel untuk mengenalkan hotelnya. Bagi wisatawan sendiri penggunaan teknologi yang ada masih mengalami kendala seperti posisi kiri dan kanan yang belum bisa dilihat yang mengakibatkan wisatawan tidak tahu arah pasti lokasi yang akan dituju. Dengan adanya aplikasi location base service (LBS) untuk memperkenalkan hotel dan wisata kuliner di Kota Pekalongan berbasis augmented reality menjadikan salah satu alternatif yang bisa digunakan untuk mengatasi kendala yang dihadapi wisatawan. Dengan memanfaatkan aplikasi LBS wisatawan dapat memanfaatkan smartphonenya untuk mengetahui informasi secara detail hotel atau wisata kuliner yang akan dituju dari tempatnya berada saat ini.

\section{KESIMPULAN}

\subsection{Kesimpulan}

Dari hasil penelitiaan yang sudah dilakukan, kesimpulan yang dapat diambil adalah sebagai berikut: 
1) Sudah terciptanya aplikasi penerapan location base service untuk memperkenalkan hotel dan wisata kuliner di Kota Pekalongan berbasis augmented reality untuk membantu wisatawan.

2) Aplikasi LBS dapat memberikan informasi navigasi interaktif dengan teknologi augmented reality yang dapat mengetahui arah dari posisi lokasi yang akan dituju.

\subsection{Saran}

Berdasarkan hasil dari penelitian yang sudah dilakukan, ada beberapa saran yang dapat dijadikan acuan untuk pengembangan kedepan, di antaranya:

1) Perlu adanya fasilitas shared lokasi ke sosial media untuk lebih mengenalkan Hotel dan Wisata Kuliner di Kota Pekalongan

2) Perlu penggunaan engine lain selain layar untuk mengetahui tingkat akurasi lokasi yang ada, sebagai pembanding antara engine layar dengan engine lainya

\section{DAFTAR PUSTAKA}

Imaniar, J., Arifin, \& Khalilullah, A. S. (2012). Aplikasi Location Based Service untuk Sistem Informasi Publikasi Acara pada Platform Android. Jurnal Proyek Akhir PENS, 28-39.

Indriastuti, D. (2018). Statistik Tingkat Penghuni Kamar Hotel Provinsi Jawa Tengah 2018. Semarang: Badan Pusat Statistik Provinsi Jawa Tengah.

Pressman, R. S., \& Maxim, B. R. (2015). Software Engineering A Practitioner's Approach Eighth Edition. New York: Mc Graw-Hill Education.

Quercia, D., Lathia, N., Calabrese, F., Lorenzo, G. D., \& Crowcroft, J. (2011). Recommending Social Events from Mobile Phone Location Data. 2010 IEEE International Conference on Data Mining, 971.

Rachman, Y., \& Wahyudi, B. (2014). Augmented Reality Kantor Pos Jakarta Timur Dalam Bentuk Location Based Services Menggunakan Platform Layar Pada Smartphone Android. Repository UG, 21-31.

Risty, A. (2012). Augmented Reality. Purwokerto: Institut Teknologi Telkom.

Safaat, N. (2013). Berbagai Implementasi dan Pengembangan Aplikasi Mobile Berbasis Android. Bandung: Informatika.

Satoto, B. D., \& Rahmanita, E. (2013). Integrasi Augmented Reality pada Mobile Virtual Tour berbasis Android untuk Pencarian Lokasi dan Rute Terdekat . Jurnal Ilmiah Mikrotek, 59-66.

Toan, P. V., \& Choo, S. Y. (2010). A Combination of Augmented Reality and Google Earth's Facilities for Urban Planning in Idea Stage. International Journal of Computer Applications, 26-34. 